\title{
Pre-Seismic Signals Recorded By The Italian RDF Network Before The Occurrence Of Some Earthquakes In Northern Italy
}

\section{Author: Valentino Straser ${ }^{1}$; Daniele Cataldi ${ }^{2-4}$; Gabriele Cataldi ${ }^{3}$; Giampaolo Gioacchino Giuliani ${ }^{4}$}

Affiliation: Department of Science and Environment UPKL, Brussels ${ }^{1}$; Radio Emissions Project, Rome (Italy) ${ }^{2}$; Radio Emissions Project, Rome (Italy) ${ }^{3}$; Permanent Foundation G. Giuliani,

$$
\text { L'Aquila (Italy) }{ }^{4}
$$

E-mail:valentino.straser@gmail.com ${ }^{1}$; daniele77c@gmail.com ${ }^{2}$;

ltpaobserverproject@gmail.com ${ }^{3}$; giuliani.giampaolo@gmail.com ${ }^{4}$

DOI: 10.26821/IJSHRE.9.1.2021.9123

\begin{abstract}
The causes that generate an earthquake can be of various kinds and, generally, there is talk of tectonic earthquakes. This type of earthquakes, unlike sudden events, such as collapses, explosions or meteoritic impacts, follow a seismic cyclicity. During the intermediate and presismic phase they are often associated with tectonic stress tension precursors of physical and chemical nature. In this study one of these aspects is analyzed: the electromagnetic interaction generated by the deformation of minerals subjected to stress in tectinically active areas. The recognition system, at the moment in the experimental phase, is the Radio Direction Finding (RDF) Network: a monitoring system that intercepts the frequencies and identifies its direction. The use of several monitoring stations makes it possible to make triangulation and locate the area of the potential epicenter already five days before the main shock. In this study two recent earthquakes occurred in Italy, in Milan and Verona, where the RDF system has proved to be an effective method of monitoring the crustal tensions in the presismic phase, thanks to the <continuous> electromagnetic monitoring network equipped with RDF technology from the Radio Emissions Project team.
\end{abstract}

\section{INTRODUCTION}

Since 2017 the authors are engaged in the <continuous> environmental electromagnetic monitorng of the natural electromagnetic background with RDF (Radio Direction Finding) technology, for the study of the possible electromagnetic precursor signals (Seismic Electromagnetic Precursors or SEPs): a project born thanks to the research carried out by the Radio Emissions Project starting from 2007. The RDF monitoring network is currently the only multiparametric monitoring network present worldwide, expressly dedicated to the monitoring of the Seismic Electromagnetic Precursors and equipped with Radio Direction Finding technology; it is composed of 4 electromagnetic monitoring stations, 3 of which are located on the Italian territory (Map. 1):

Keywords: earthquake prediction, Radio Direction Finding, radio anomalies, seismic precursors.

Valentino Straser; Daniele Cataldi; Gabriele Cataldi; Giampaolo Gioacchino Giuliani, Volume 9 Issue 1, pp 
Volume 9 Issue 1 January 2021

1) Lariano (Roma, Italy) RDF station - Lat: 41.728799N, Long: 12.843205E.

2) Ripa-Fagnano (L'Aquila, Italy) RDF station Lat: 42.265690N, Long: 13.583793E.

3) Pontedera (Pisa, Italy) RDF station - Lat: 43.672445N, Long: 10.640100E.

Through the analysis of RDF data provided by these electromagnetic monitoring stations, the authors were able, in the past, to identify some areas of the Italian peninsula within which seismic events of low or medium-low intensity were subsequently recorded [1] [2] [3] [4] [5] [6] [7] [8] [9] [10] [11] [12] [13].
Between 17 and 29 December 2020 on the Italian territory (Northern Italy) three M3+ seismic events were recorded (Map. 1):

- ML 3.8 Milan (Milan, Italy) earthquake, depth $55 \mathrm{~km}$ - December 17, 2020 at 15:59:22 UTC.

- ML 3.4 Salizzole (Verona, Italy) earthquake, depth $11 \mathrm{~km}$ - December 29, 2020 at 13:02:40 UTC.

- ML 4.4 Salizzole (Verona, Italy) earthquake, depth $9 \mathrm{~km}$ - December, 292020 at 14:36:57 UTC.

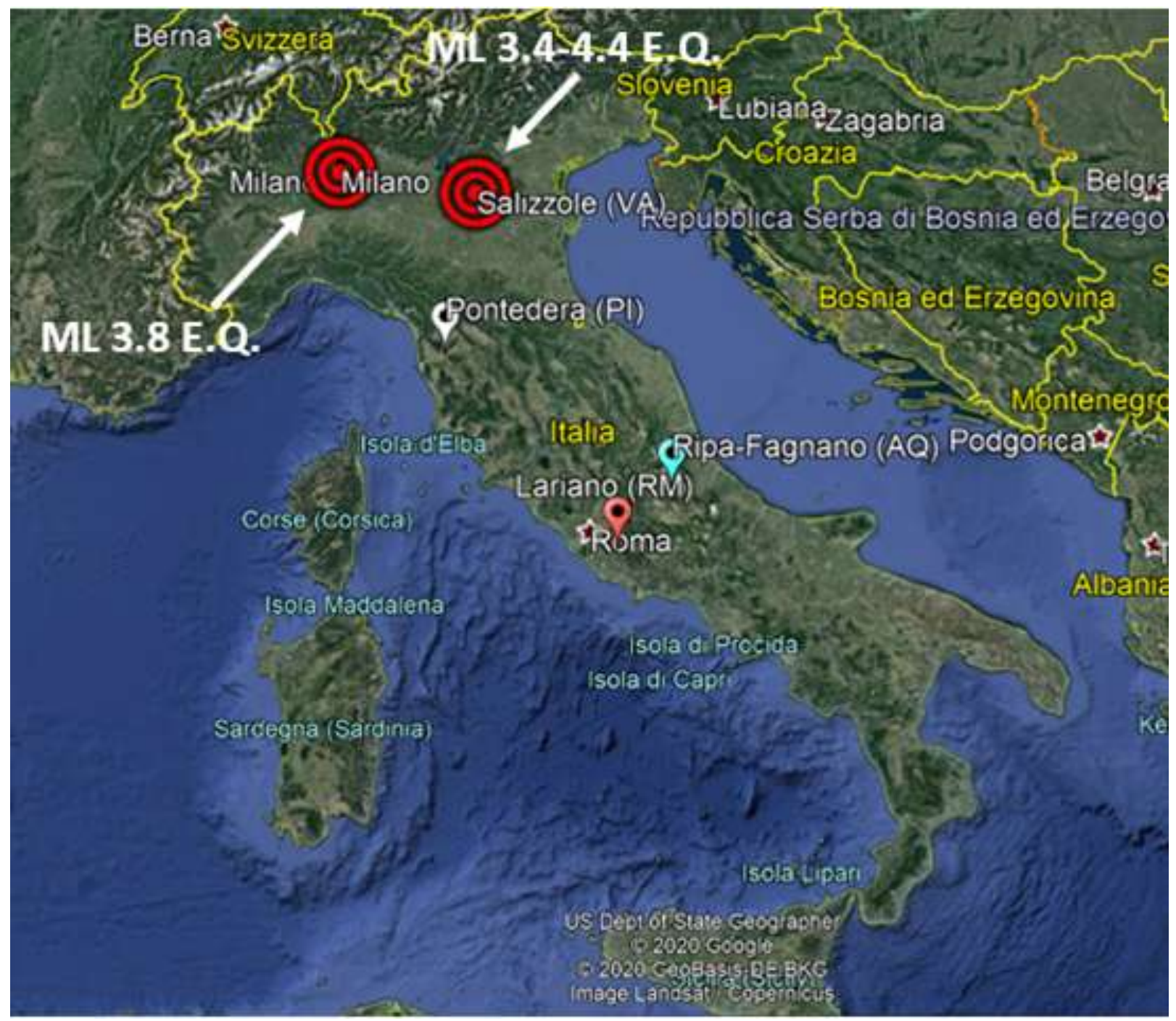

Map 1: Seismic epicenters of Milan (MI) and Salizzole (VA). The map to the left are visible the Italian seismic epicenters (in red) of Salizzole (Verona, Italy) and Milan (Milan, Italy) (Northern Italy): ML 3.8 Milan (Milan,

Italy) Earthquake, Depth $55 \mathrm{~km}$ - December 17, 2020 at 15:59:22 utc; ML 3.4 Salizzole (Verona, Italy) Earthquake, Depth $11 \mathrm{~km}$ - December 29, 2020 at 13:02:40 utc; ML 4.4 Salizzole (Verona, Italy) Earthquake, Depth $9 \mathrm{~km}$ - December, 292020 at 14:36:57 UTC. The other indicators (blue, white and red, located further South) represent the places where the RDF (Radio Direction Finding) monitoring stations, developed by the Radio Emissions Project, are located from 2017: in red the Lariano (Rome, Italy) RDF station - LAT: 41.728799 N, Long: 12.843205 and; Blank the Ripa-Fagnano (L'Aquila, Italy) RDF station - Lat: 42.265690 N, Long: 
Volume 9 Issue 1 January 2021

\section{3,583793 and; In blue the Pontedera (Pisa, Italy) RDF station - Lat: 43.672445 N, Long: 10.640100 E. Credits: Radio Emissions Project, Google Earth.}

These seismic events caused a particular stir in Italy among the population and among scholars because there was a concern that further earthquakes could occur within a short period of time. This concern was justified by the fact that for several days and hours the RDF monitoring network had been identifying a series of electromagnetic signals having the area of Northern Italy as their azimuth. In this work, RDF monitoring data will be presented which allowed the authors to identify the Italian geographical areas within which the three M3+ seismic events occurred in Northern Italy were then recorded.

\section{METHODS AND DATA}

The Italian RDF (Radio Direction Finding) monitoring network identified a series of natural electromagnetic signals identifying its emission source (point of genesis) through the technique of the "radio triangulation", to which the RDF detection system is essentially based.

The triangulation of electromagnetic signals is made possible thanks to the capacity that each single RDF detection station has: each RDF station is able to trace the azimuth of each electromagnetic signal captured with respect to the position of the RDF station itself. Knowing, therefore, the geographical position of each RDF station it is possible to determine the geographical position of the natural carrier that emits radiofrequency by performing a triangulation of azimuth supplied by each single RDF station with respect to a certain electromagnetic signal. Studies carried out by the Radio Emissions Project starting from 2018 (1) showed that it is possible to identify well in advance (of hours or days), the occurrence of earthquakes not only on Italian soil but also on the entire Earth globe, thanks to the use of the RDF monitoring network and triangulation technique developed by the authors.
Using this technique, the authors have been able to identify on the Italian territory of the areas within which M3+ seismic events were subsequently recorded:

1) The first earthquake considered in this study is that of magnitude $\mathrm{ml} 3.8$ of 17-12-2020 at around: $3 \mathrm{~km} \mathrm{~W}$ Milan (Milan, Italy) with geographical coordinates (Lat, Lon ) $45.47 \mathrm{~N}$, $9.15 \mathrm{E}$ at a depth of $55 \mathrm{~km}$.

2) The second earthquake considered is that of magnitude ML 3.4 of 29-12-2020 at around: 2 km W Salizzole (Verona, Italy), with geographical coordinates (Lat, Lon) $45.24 \mathrm{~N}$, $11.06 \mathrm{E}$ at a depth of $11 \mathrm{~km}$.

3) The third earthquake considered is that of magnitude ML 4.4 of 29-12-2020 hours 14:36:57 (UTC) took place in the area: $3 \mathrm{~km}$ W Salizzole (Verona, Italy), with geographical coordinates (Lat, Lon) $45.24 \mathrm{~N}$, $11.04 \mathrm{E}$ at a depth of $9 \mathrm{~km}$.

The authors believe that this type of radio emissions are produced through the creation of microfractures in the terrestrial crust (piezomagnetic and piezoelectric effect) following accumulation of tectonic stress, as proposed by many researchers starting from the 1980 s [14] [15] [16].

\subsection{MILAN EARTHQUAKE (ITALY) - ML3.8}

Regarding the earthquake in Milan (ML 3.8), the colorimetric map of the Italian RDF network highlighted the exact position of the seismic epicenter (Fig. 1), Compared to the colored lines (azimuth) highlighted within the dynamic spectrograms generated by the detection system developed by the Radio Emissions Project and which will be analyzed later. 
Volume 9 Issue 1 January 2021

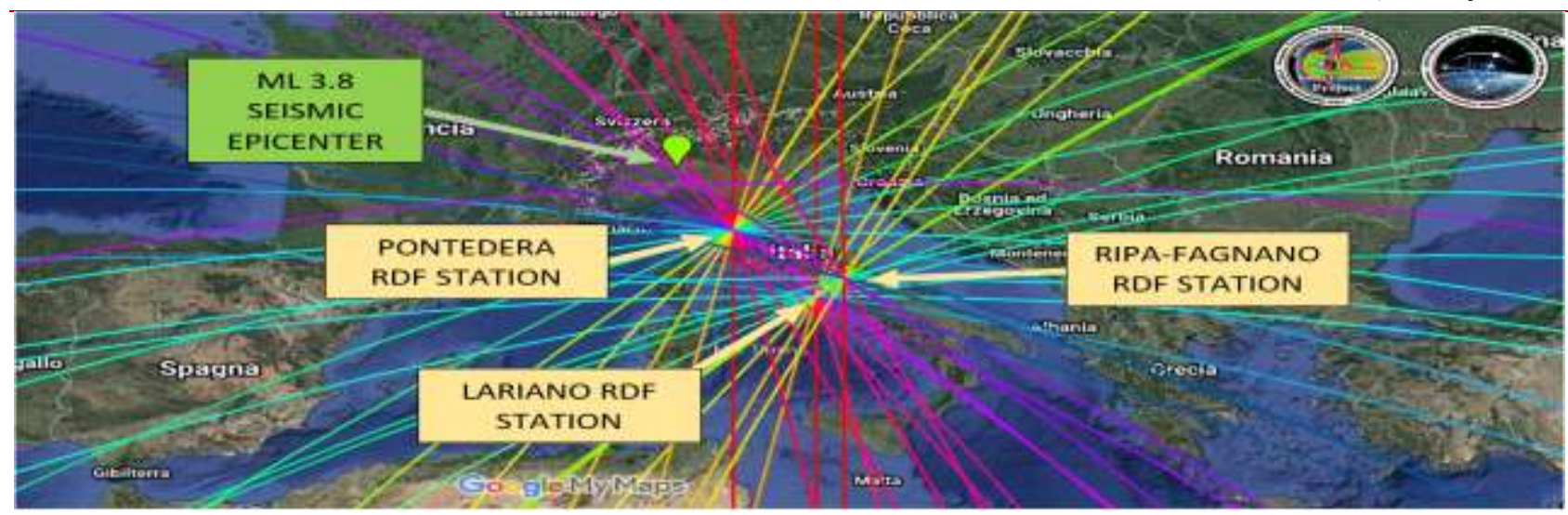

Fig. 1: Colorimetric map of the RDF worldwide network, developed by the Radio Emissions Project. It shows the position of the three Italian RDF stations and the position of the ML3.8 seismic epicenter. Credits: Radio Emissions Project, Google Maps.

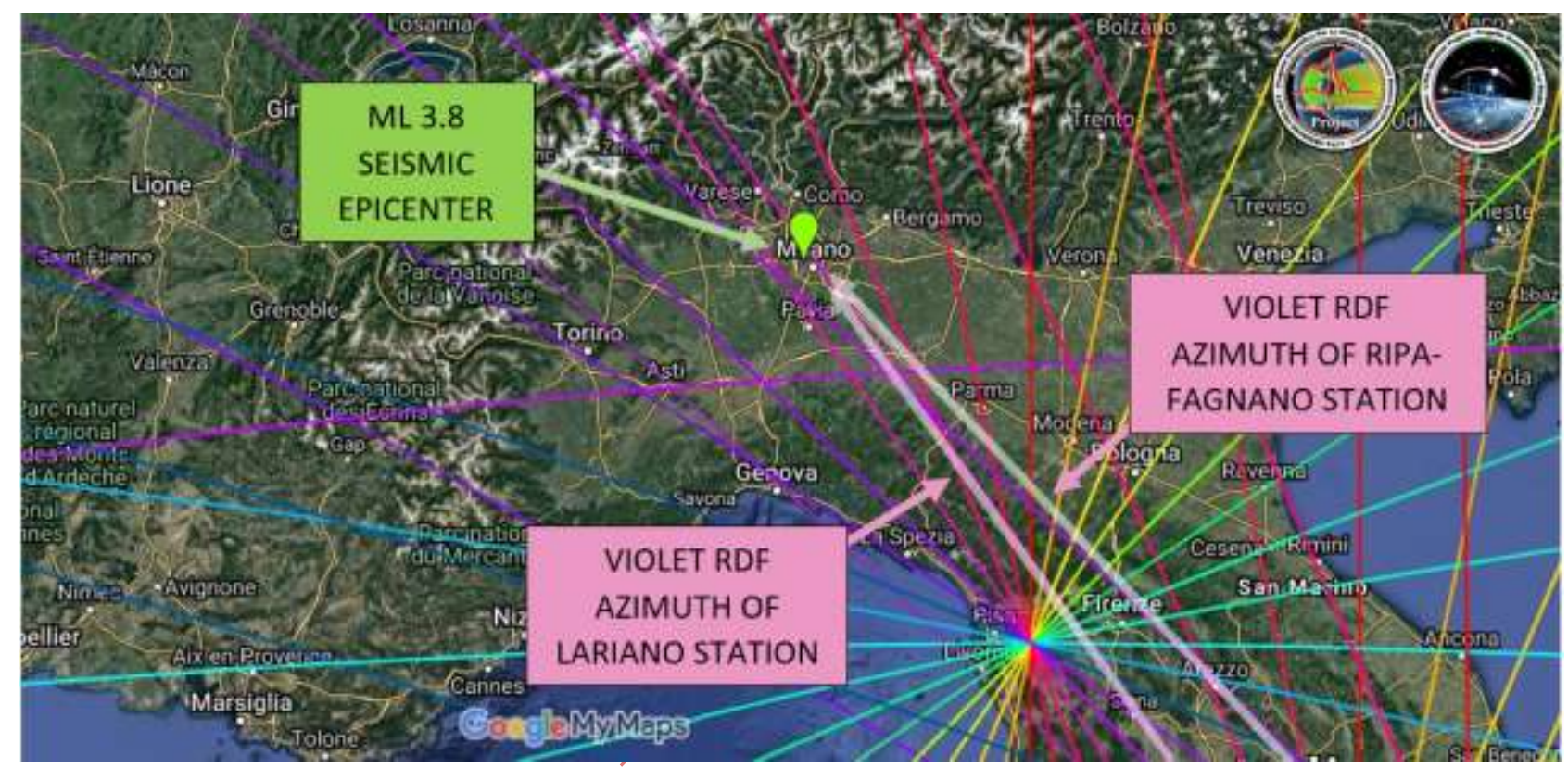

Fig. 2: Colorimetric map of the RDF worldwide network, developed by the Radio Emissions Project. The map shows the location of the related colorimetrics-azimuth, generated by each Italian RDF station, and able to indicate the hypocentral area of ML3.8 earthquake. Credits: Radio Emissions Project, Google Maps.

Observing the Fig. 1-2 it is evident that the azimuters associated with the ML3.8 seismic event are those of violet color of which two of the Italian RDF stations have actually had instrumental confirmation. The RDF stations responsible for instrumental detection were those of Lariano (Rome, Italy) and that of RipaFagnano (L'Aquila, Italy), situated both in Central Italy. 
Volume 9 Issue 1 January 2021

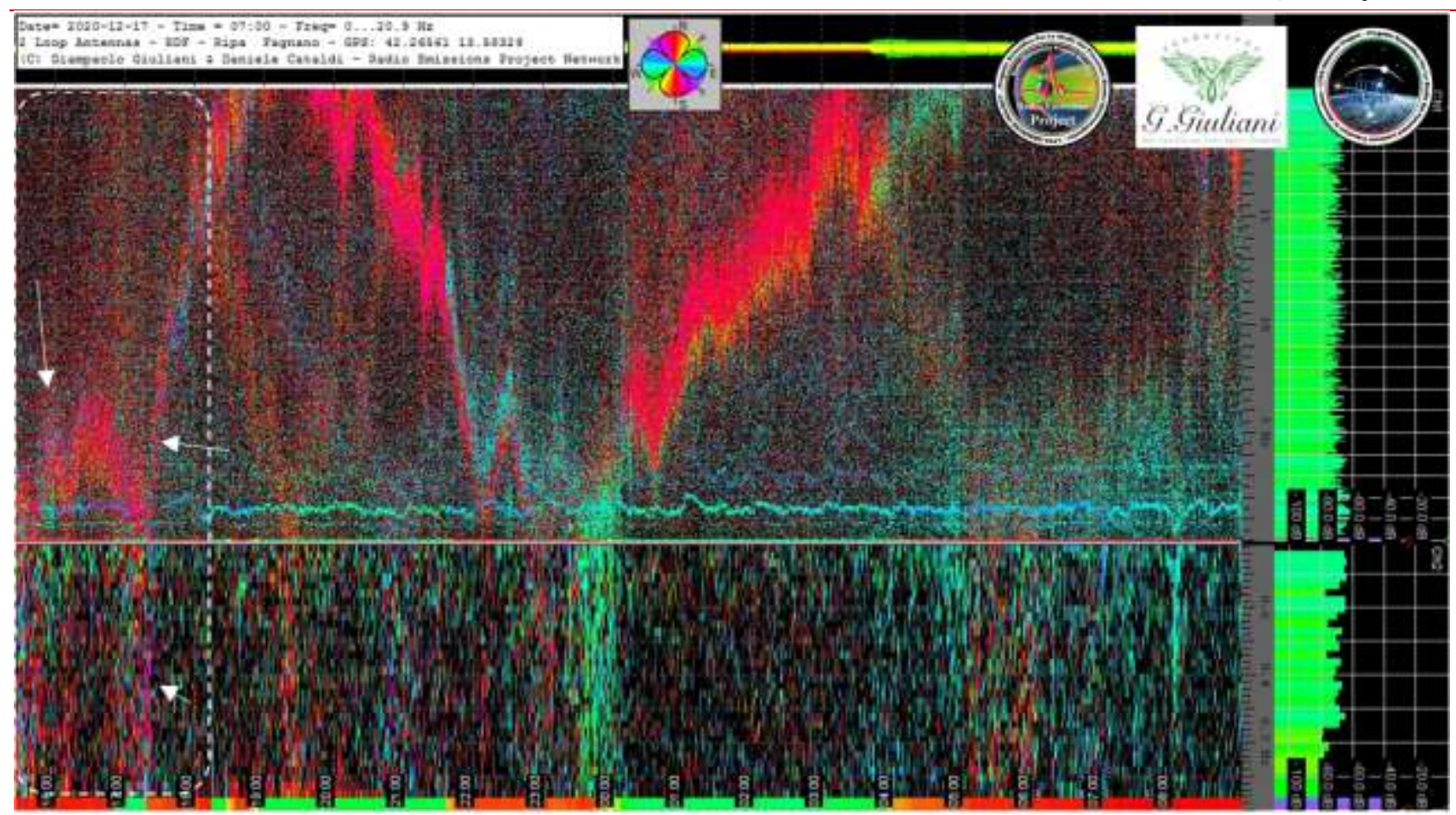

Fig. 3: Spectrogram of Ripa-Fagnano RDF station (L'Aquila, Italy). It evidence of the appearance of electromagnetic signals associated precisely to the aximut of the seismic epicenter. On the axis of ordering the electromagnetic frequency and on the axis of the abscissa the time of appearance of the registered signals. Credits: Radio Emissions Project, Permanent Foundation G. Giuliani.

The first purple signal was manifested from 16:00 UTC at 17:30 UTC approximately, of December 16, 2020 with a frequency between $0.03 \mathrm{~Hz}$ and $15 \mathrm{~Hz}$. The registration was carried out by Ripa-Fagnano RDF station (L'Aquila, Rome), on a carrier signal with red azimut (Fig. 3).

The second series of signals (peaks), instead appeared from 04:00 UTC to 04:20 UTC, and again, from 10:30 UTC to 10:40 UTC of December 17, 2020. These signals had an average frequency of $2.5 \mathrm{~Hz}$ (SELF Super Extremely Low Frequency band) Fig. 4; the natural geomagnetic background has highlighted, already at 11:30 UTC of January 16, 2020, epicentral azimut at a frequency of $0.01 \mathrm{~Hz}$ (Fig. 4). The Italian stations have therefore identified and recorded the appearance of very obvious electromagnetic signals which presented as the main characteristic the same azimut of the area where the earthquake was then verified. In this case the coloring of the electromagnetic signals themselves, present on dynamic spectrograms (Fig. 3 e 4), it indicated the precise azimut of origin, allowing to identify the geographical area, located in northern Italy.
2.2 SALIZZOLE EARTHQUAKE

\section{(VERONA, Italy) - ML3.4 and ML4.4}

Very interesting electromagnetic signals were also recorded for the earthquakes that occurred near Salizzole (Verona, Italy). Considering the azimuth data of the signals, the colorimetric map of the Italian RDF network highlighted the exact location of the seismic epicenter (Fig. 5).

The RDF station of Pontedera (Pisa, Italy), that of Lariano (Rome, Italy) and from that of Ripa-Fagnano (L'Aquila, Italy) managed by the Foundation Giuliani showed a coherent azimuth with the epicentral area of Salizzole (Verona, Italy). The signals appeared on the dynamic spectrograms highlighted by the RDF network were immediately very clear, so much so that the authors had decided to follow the evolution of the records more attention: all this took place several days before the two earthquakes (ML 3.4 and ML 4.4) occurred. The first signals recorded by RDF station of Ripa-Fagnano (L'Aquila, Italy) appeared on December 24, 2020 at 10:30 UTC and are overred for many hours, until 08:00 UTC of December 25, 2020: 23 hours continuous. These signals had an electromagnetic frequency between $0.03 \mathrm{~Hz}$ and over $20 \mathrm{~Hz}$ (beyond the frequency limit observed by the 
Volume 9 Issue 1 January 2021

station). The signal clearly evident on the dynamic spectrograms (Fig. 7, 7b, 8, 9), appeared clearly together with the colorimetry variation of the natural geomagnetic background $(0.01 \mathrm{~Hz})$, even if with a different azimuth compared to the main signal just described.

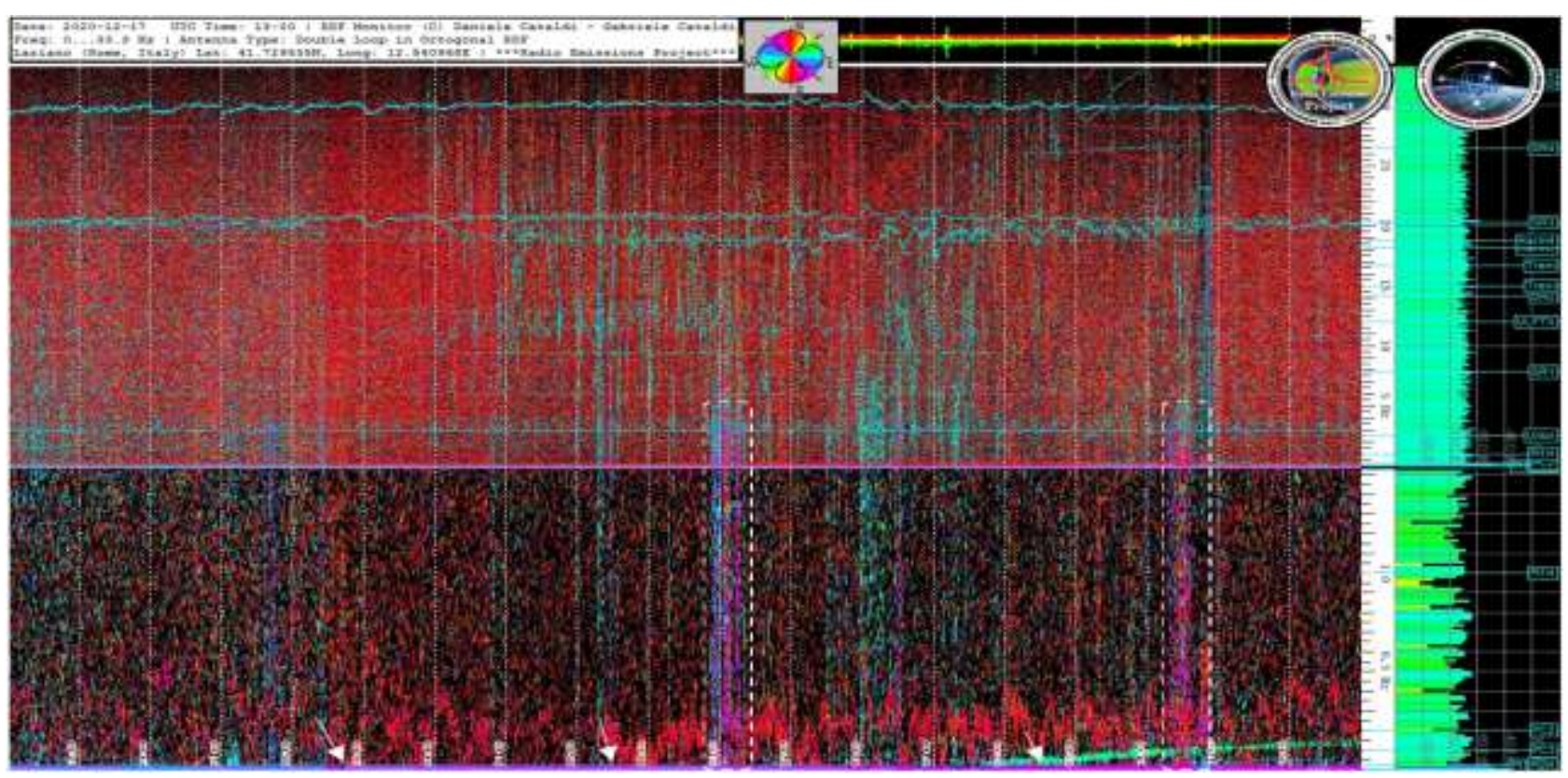

Fig. 4: Dynamic spectrogram generated by the RDF station of Lariano (Rome, Italy). It highlights the presence of electromagnetic signals, appearing to different frequency, having the hypocentral position of the earthquake as azimuth. On the axis of ordering the electromagnetic frequency and on the axis of the abscissa the time of appearance of the registered signals. Credits: Radio Emissions Project, Permanent Foundation G. Giuliani.

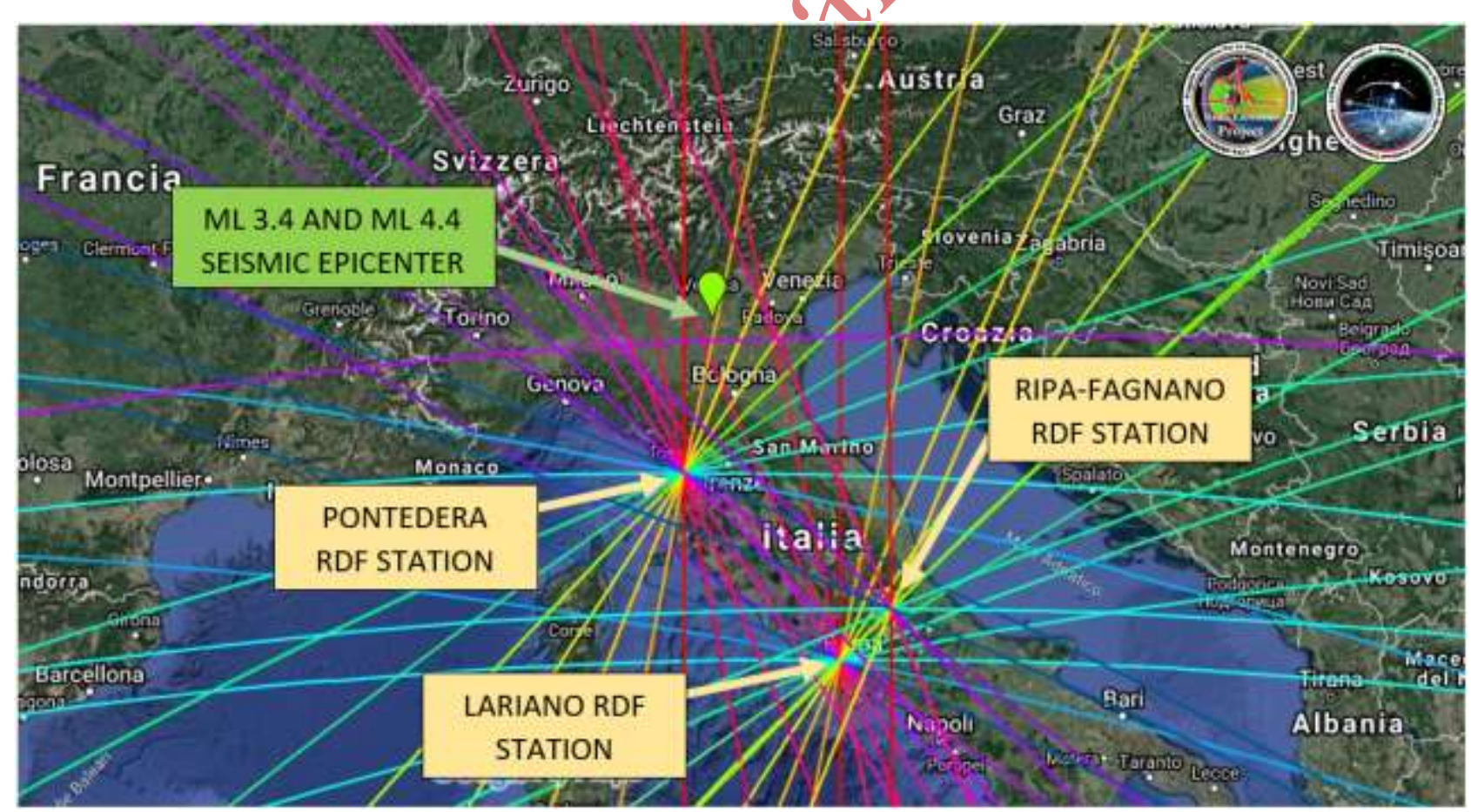

Fig. 5: Colorimetric map of the RDF worldwide network, developed by the Radio Emissions Project. It shows the position of the various Italian stations and the position of the seismic epicenter. Credits: Radio Emissions Project, Google Maps. 
Volume 9 Issue 1 January 2021

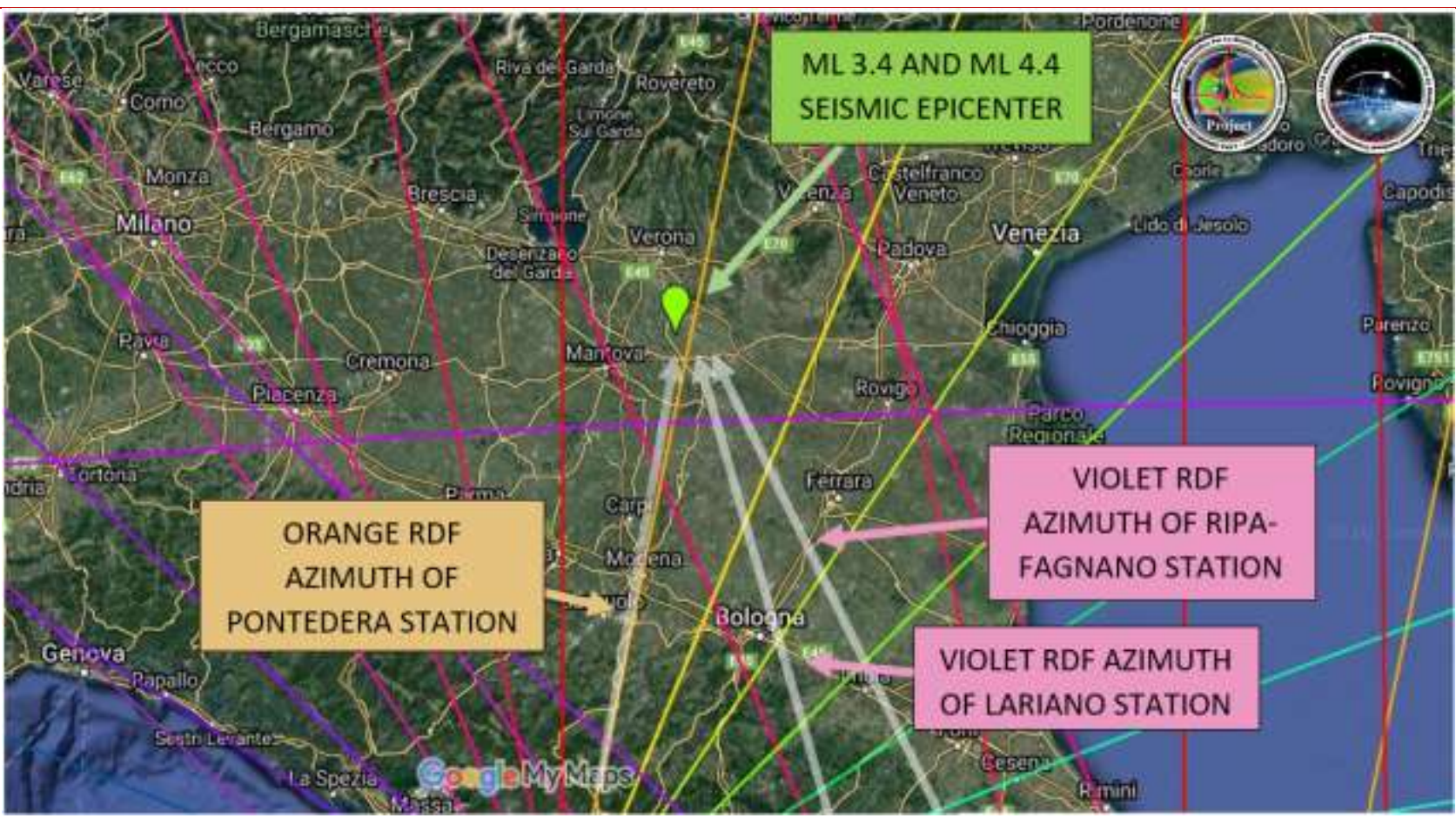

Fig. 6: Colorimetric map of the RDF worldwide network, developed by the Radio Emissions Project. It shows the position of the various Italian stations and the position of the seismic epicenter. Credits: Radio Emissions Project, Google Maps.

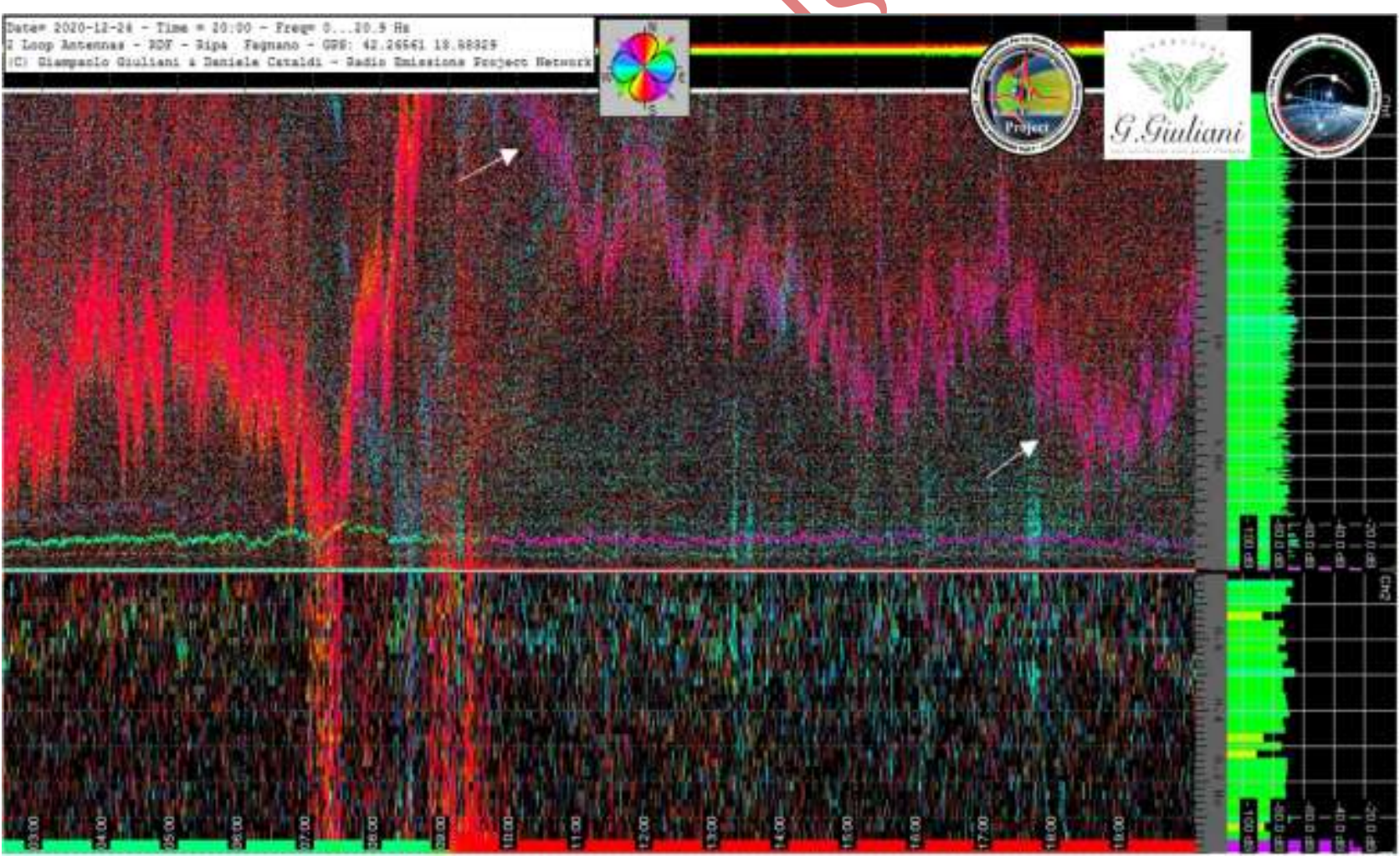

Fig. 7: Spectrogram of Ripa-Fagnano RDF station (L'Aquila, Italy). It evidence of the appearance of electromagnetic signals associated precisely to the aximut of the seismic epicenter. On the axis of ordering the electromagnetic frequency and on the axis of the abscissa the time of appearance of the registered signals. Credits: Radio Emissions Project, Permanent Foundation G. Giuliani. 


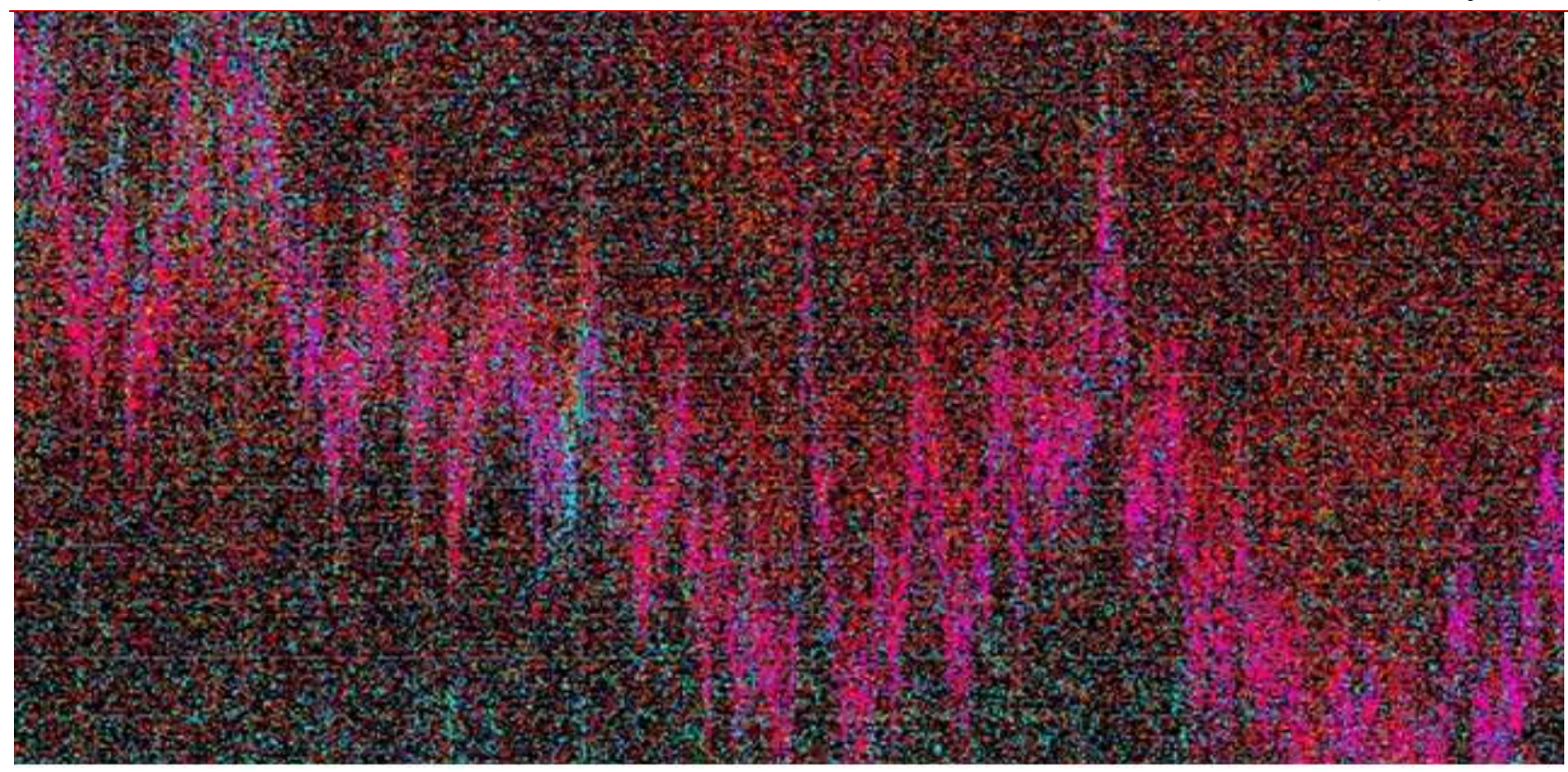

Fig. 7b: Spectrogram of Ripa-Fagnano RDF station (L'Aquila, Italy). It highlights (in enlargement) the morphology of the recorded pre-seismic electromagnetic signal. Credits: Radio Emissions Project, Permanent Foundation G. Giuliani.

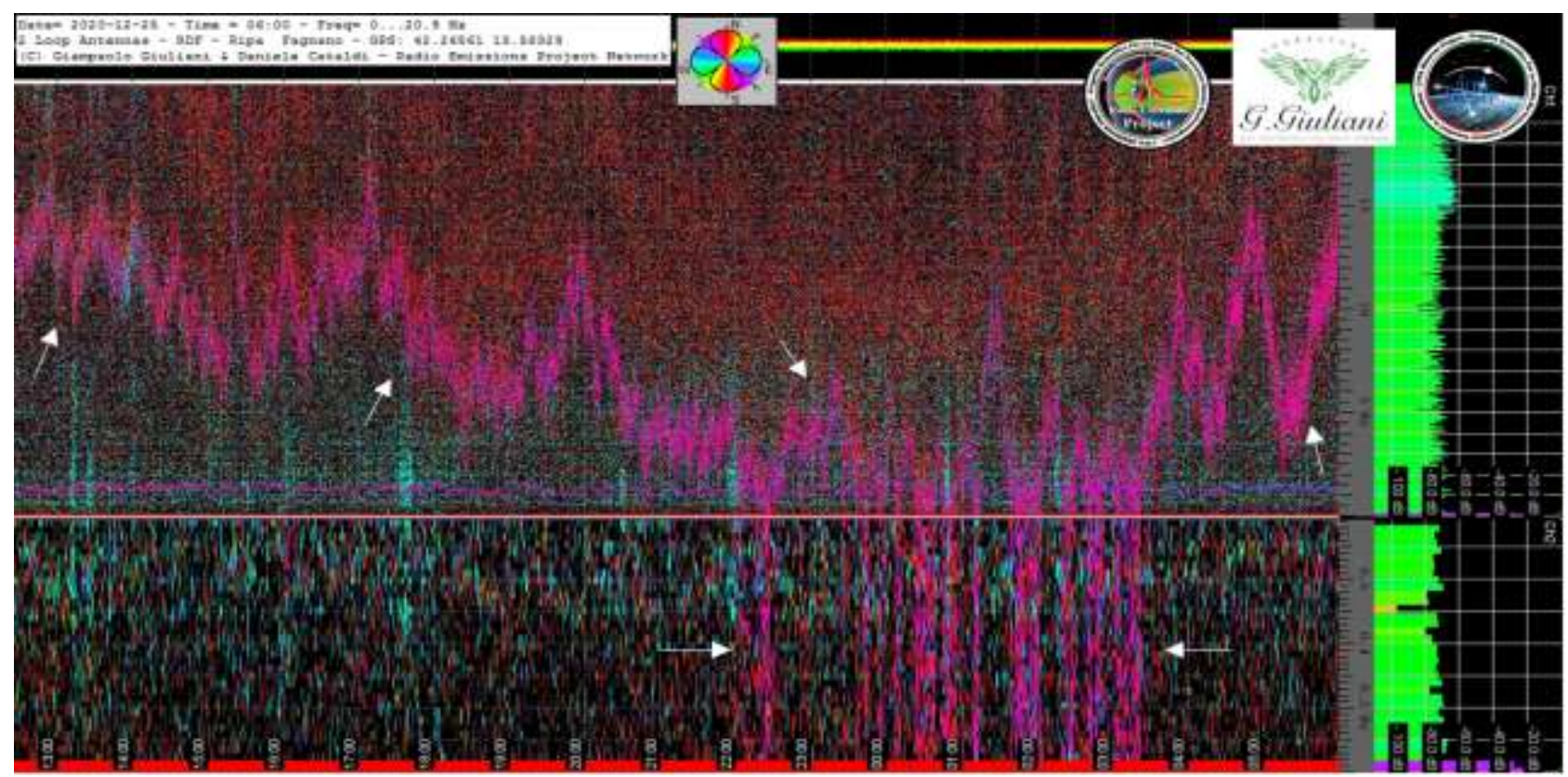

Fig. 8: Spectrogram of Ripa-Fagnano RDF station (L'Aquila, Italy). It evidence of the appearance of electromagnetic signals associated precisely to the aximut of the seismic epicenter. On the axis of ordering the electromagnetic frequency and on the axis of the abscissa the time of appearance of the registered signals. Credits: Radio Emissions Project, Permanent Foundation G. Giuliani.

The spectral imprint of this signal (purple color) is extremely special and evident, compared to the other signals present and identified in the spectrogram from Ripa-Fagnano RDF station (L'Aquila, Italy). 
Volume 9 Issue 1 January 2021

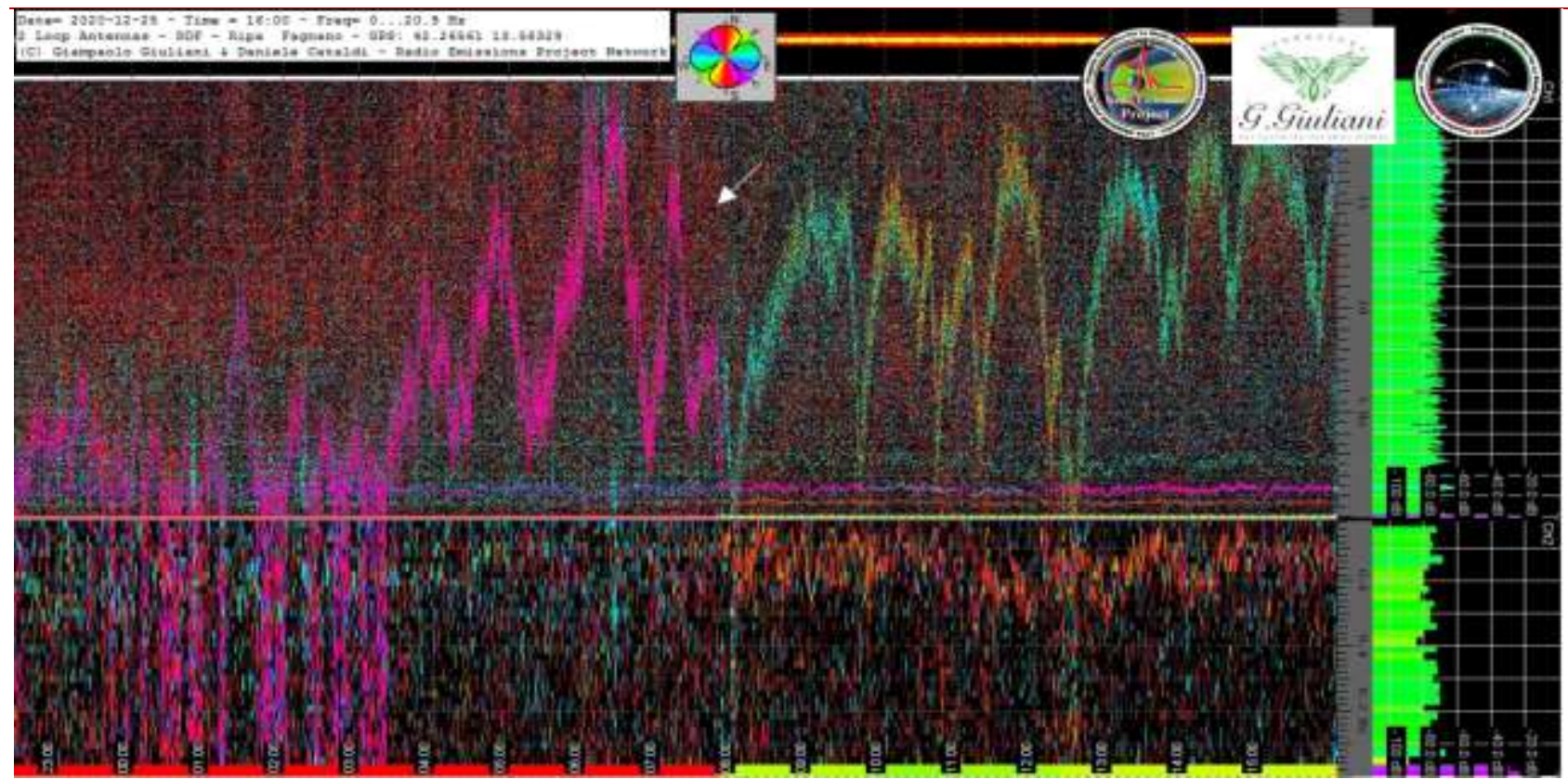

Fig. 9: Spectrogram of Ripa-Fagnano RDF station (L'Aquila, Italy). It evidence of the appearance of electromagnetic signals associated precisely to the aximut of the seismic epicenter. On the axis of ordering the electromagnetic frequency and on the axis of the abscissa the time of appearance of the registered signals. Credits: Radio Emissions Project, Permanent Foundation G. Giuliani.

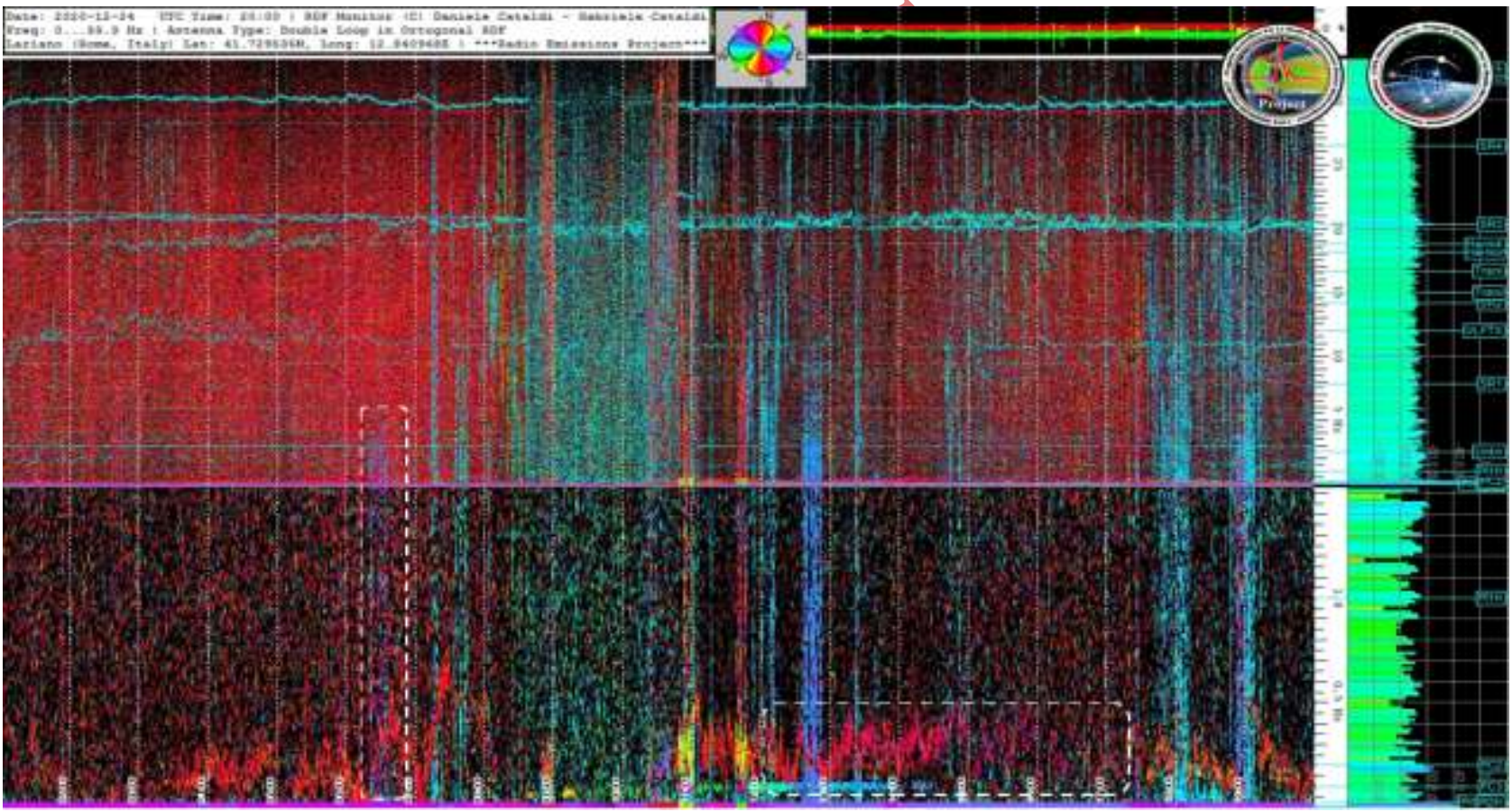

Fig. 10: Dynamic spectrogram generated by the RDF station of Lariano (Rome, Italy). It highlights the presence of electromagnetic signals, appearing to different frequency, having the hypocentral position of the earthquake as azimuth. On the axis of ordering the electromagnetic frequency and on the axis of the abscissa the time of appearance of the registered signals. Credits: Radio Emissions Project.

Other interesting signals were detected by Lariano (Rome, Italy) RDF station, registered starting on December 24, 2020 (Fig. 10). Also in this case the signals have been very obvious. The first signal appeared around 06:30 UTC with an average electromagnetic frequency of about $2.5 \mathrm{~Hz}$. Other 
Volume 9 Issue 1 January 2021

obvious and particular signal is that appeared between 12:00 UTC and 17:00 UTC, as of December 24, 2020 with electromagnetic frequency between 0.3 and 0.4 $\mathrm{Hz}$ (Fig. 10). At this time and even previously (December 23, 2020), the azimuth afferent to the geomagnetic band highlighted a red color, ie in the direction of northern Italy. Other signals, even if less intense than December 24, 2020, appeared from December 26, 2020 at 16:00 UTC until 12:00 UTC of December 27, 2020 with an average electromagnetic frequency of about $8 \mathrm{~Hz}$. Also in this case the RDF station that highlighted this important signal was that of Ripa-Fagnano (L'Aquila, Italy) as visible in Fig. 11, 12 (purple signal).

Going to better observe the signal recorded on December 24, 2020, with frequency between $0.3 \mathrm{~Hz}$ and $0.4 \mathrm{~Hz}$, it is found that this had a reddish azimut tending to the light purple that later, in a few minutes, changed azimut (dark purple) as visible in Fig. 10b.

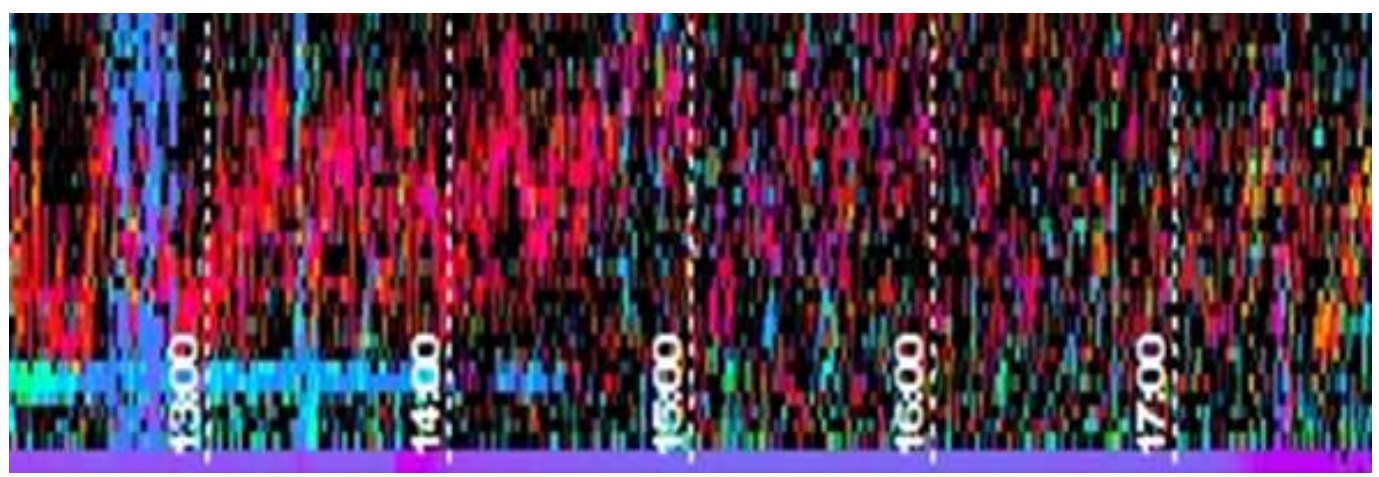

Fig. 10b: Dynamic spectrogram generated by the RDF station of Lariano (Rome, Italy). It highlights (in enlargement) the characteristics of the violet radio-anomaly recorded by the RDF station. Credits: Radio Emissions Project.

The authors believe that the variation of azimuth can explain through morphological variations of the electromagnetic dipole coming from the lithosphere in relation to the distribution of tectonic stress and the geological characteristics present in the earthquake preparation area. In other words it is hypotheses of the authors to explain these variations of azimut as a sudden variations of tectonic stress present in the area of preparation of the earthquake that are able to activate electromagnetic dipoles in different areas of the terrestrial crust [17]: a lithosphere in continuous evolution therefore and not static, characterized by complex geological structures. In physics the electromagnetic field is the field that describes electromagnetic interaction. It consists of the combination of the electric field and the magnetic field and is generated locally from any distribution of electric charge and electric current variable over time, propagating in the space in the form of electromagnetic waves [18]. What is recorded by the RDF detection system is therefore a photograph of the electromagnetic activity than it happens at the crustal level in the operating range of the system which must be remembered, is of the order of thousands of $\mathrm{km}$. For this reason, on the spectrogram there are a large number of electromagnetic traces each of which has its specific azimut of origin. Attention must therefore be maintained on the variations in azimut as well as on the intensity of the spectral fingerprints monitored by the RDF system. Another characteristic that must be kept under control is the morphology, the spectral impression of the radio emissions present on the spectrogram in relation to the temporal variable: this type of analysis allows to discriminate natural electromagnetic sources from the anthropogen or electromagnetic interference of anthropic nature from natural emissions that can be candidates as possible seismic precursors. Considering what has just been stated it is evident that if there is no experience in the interpretation of the spectral fingerprints of the electromagnetic signals contained in a dynamic spectrogram, it is not possible to carry out an electromagnetic monitoring project dedicated to electromagnetic seismic precursors. A few hours and a few minutes before the earthquakes occurred a further anomalous radio emission appeared, starting from 09:00 UTC of December 29, 2020 and continuing beyond the earthquake, ie until 15:00 UTC. The electromagnetic frequency of this issue, appeared close to the temporal time of the seismic event, was recorded between $0.03 \mathrm{~Hz}$ and $21 \mathrm{~Hz}$ (Fig. 13). This is the evidence that Ripa-Fagnano (L'Aquila, Italy) RDF station reported the epicentral azimuter precisely also considering the temporal distance of the seismic event, compared to the time of signal appearance is obvious that These signals, having the same azimut of the point 


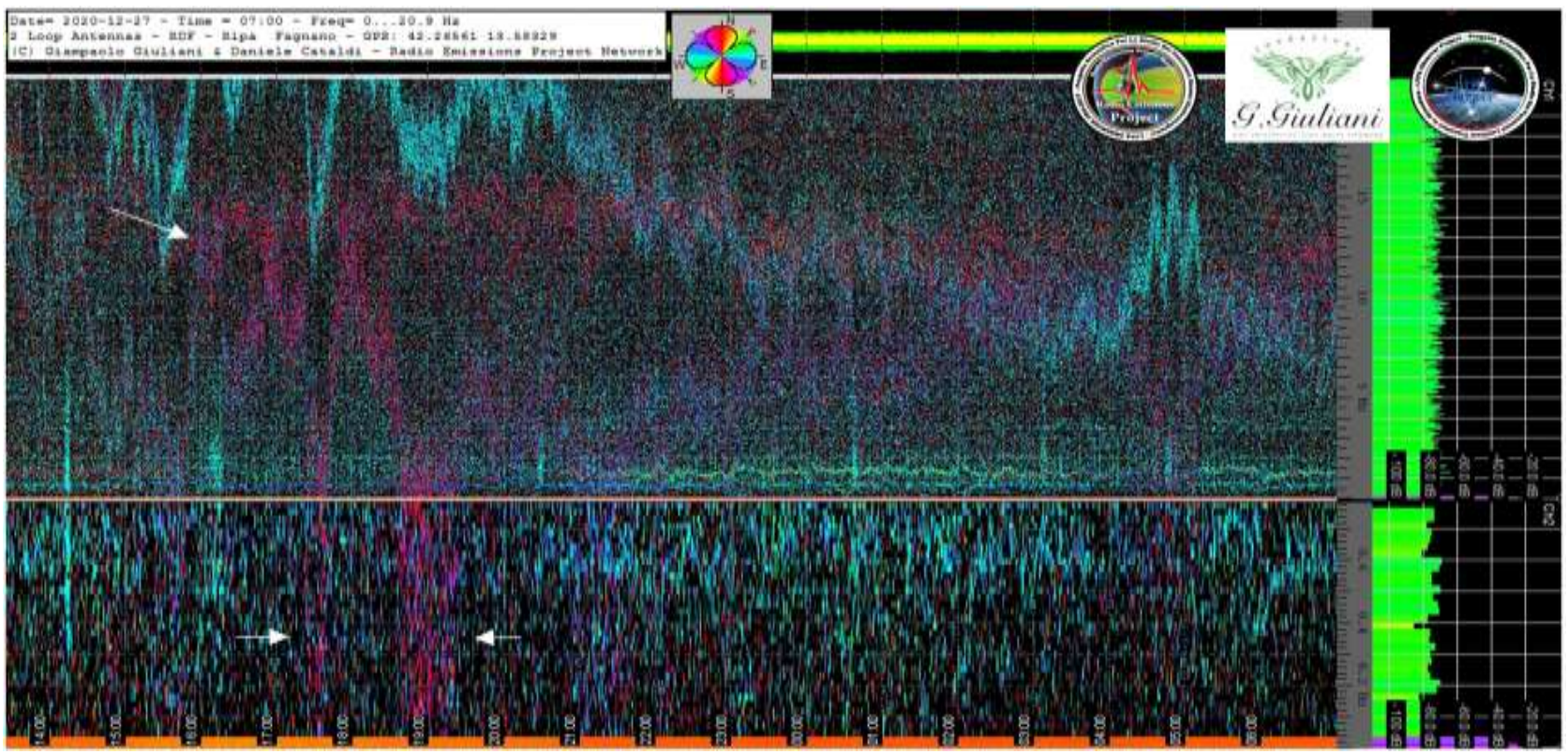

Fig. 11: Dynamic spectrogram of Ripa-Fagnano RDF station (L'Aquila, Italy). It evidence of the appearance of electromagnetic signals associated precisely to the aximut of the seismic epicenter. On the axis of ordering the electromagnetic frequency and on the axis of the abscissa the time of appearance of the registered signals. Credits: Radio Emissions Project, Permanent Foundation G. Giuliani.

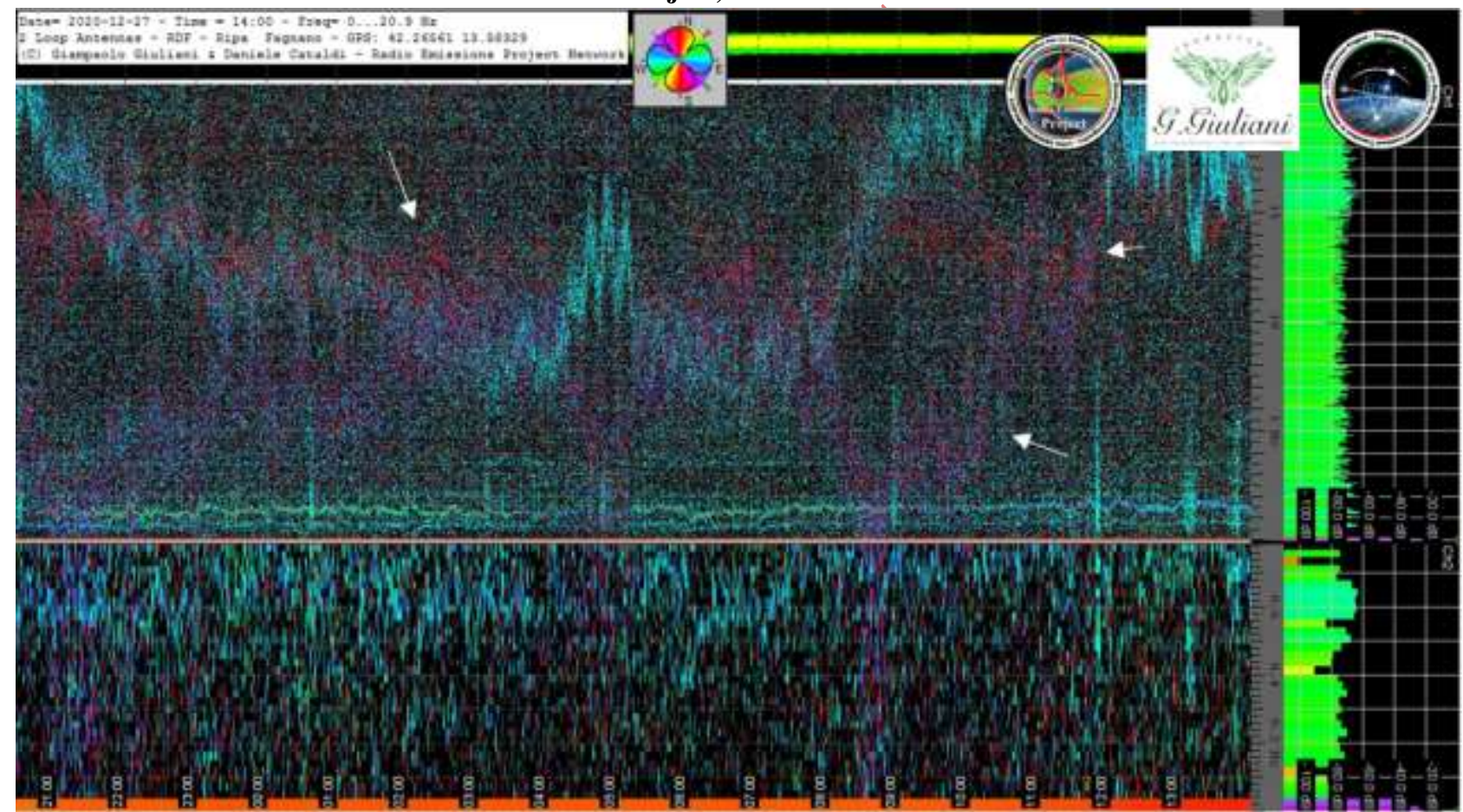

Fig. 12: Dynamic spectrogram of Ripa-Fagnano RDF station (L'Aquila, Italy). It evidence of the appearance of electromagnetic signals associated precisely to the aximut of the seismic epicenter. On the axis of ordering the electromagnetic frequency and on the axis of the abscissa the time of appearance of the registered signals. Credits: Radio Emissions Project, Permanent Foundation G. Giuliani. 


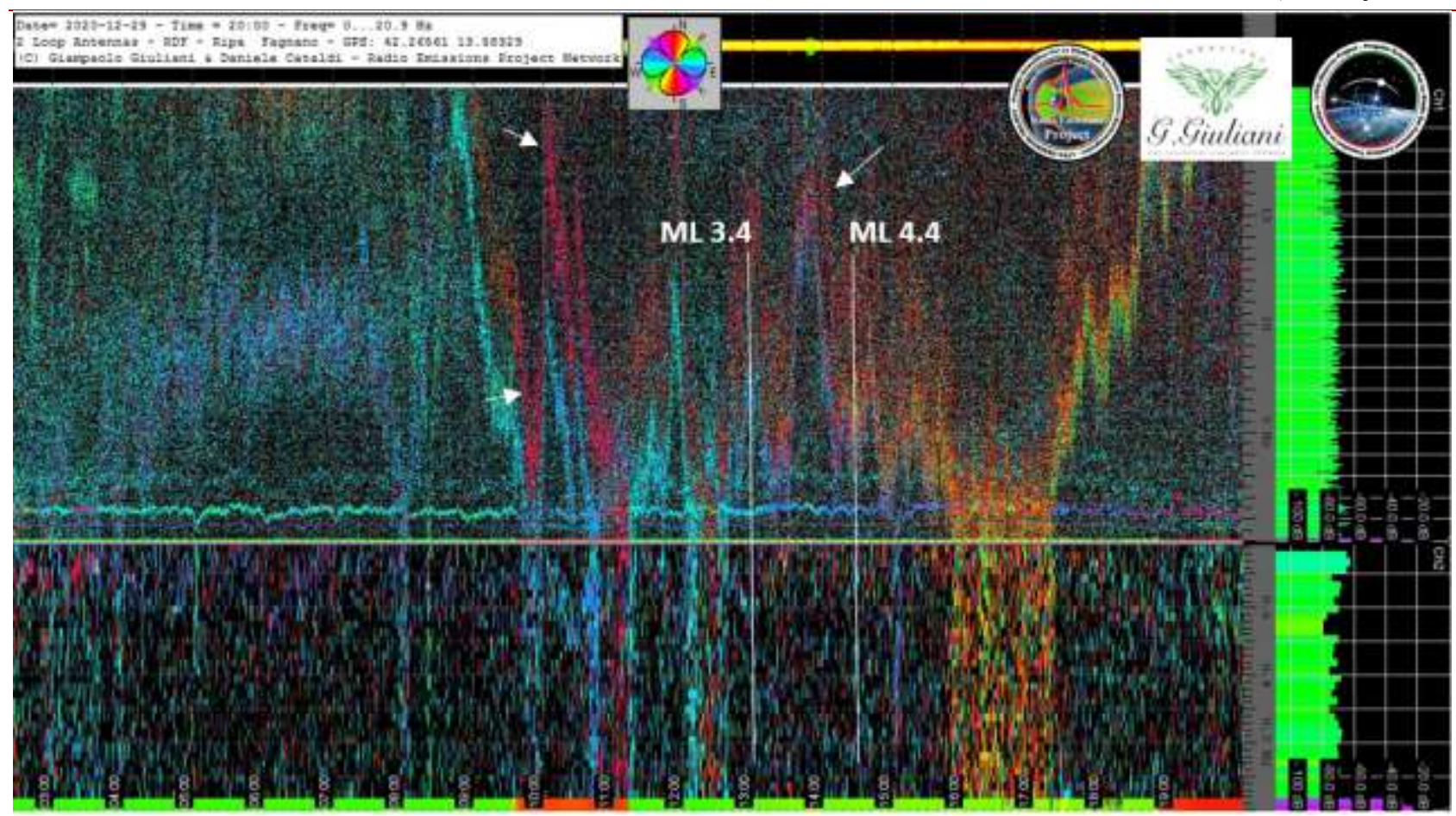

Fig. 13: Dynamic Spectrogram generated by Ripa-Fagnano RDF station (L'Aquila, Italy). It evidence of the appearance of electromagnetic signals associated precisely to the aximut of the seismic epicenter. On the axis of ordering the electromagnetic frequency and on the axis of the abscissa the time of appearance of the registered signals. Credits: Radio Emissions Project, Permanent Foundation G. Giuliani.

the seismic event, was recorded between $0.03 \mathrm{~Hz}$ and $21 \mathrm{~Hz}$ (Fig. 13 and 13b). This is the evidence that Ripa-Fagnano (L'Aquila, Italy) RDF station reported the epicentral azimuter precisely also considering the temporal distance of the seismic event, compared to

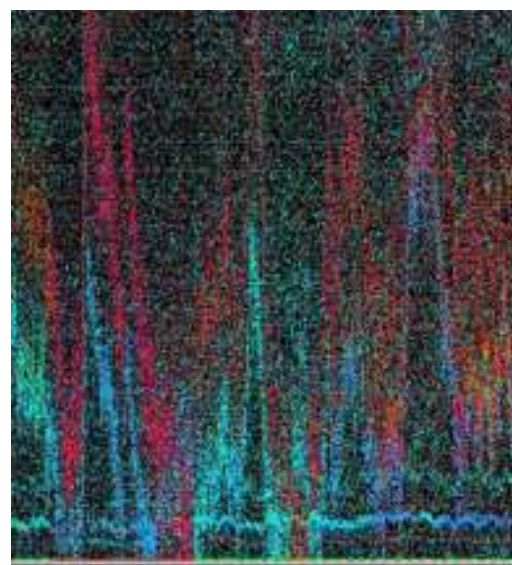

Fig. 13b: Dynamic Spectrogram generated by Ripa-Fagnano RDF station (L'Aquila, Italy). On the axis of ordering the electromagnetic frequency and on the axis of the abscissa the time of appearance of the registered signals. It highlights (in enlargement) the characteristics of the violet radio-anomaly recorded by the RDF station. In this case the appearance of electromagnetic signals that the detection system has highlighted in nicknaps, indicating the azimut of origin from central Italy, with several hours of notice before earthquakes 
Volume 9 Issue 1 January 2021

occur. The evidence of these emissions at a close time distance compared to the time of occurrence of the two earthquakes, indicates that these signals possess a close relationship with the seismic events in question. Credits: Radio Emissions Project, Permanent Foundation G. Giuliani.

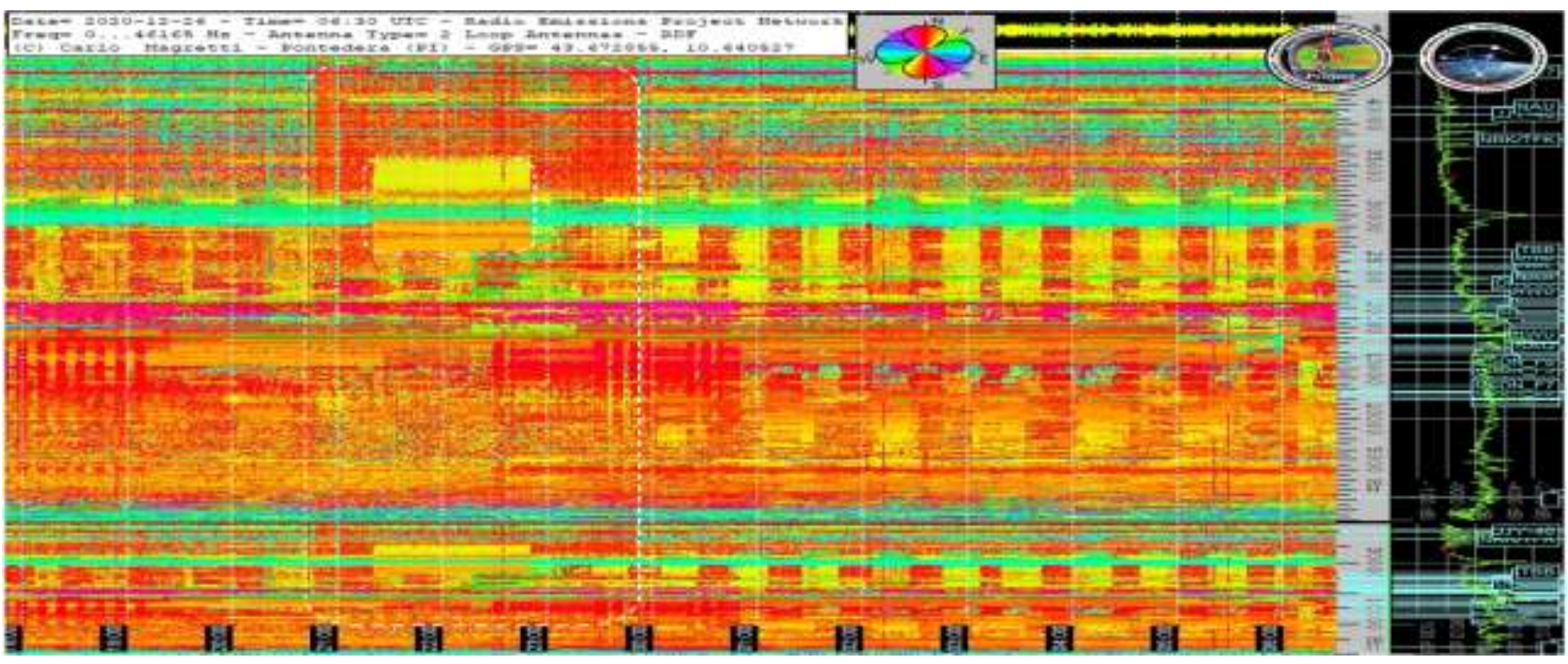

Fig. 13b: Dynamic Spectrogram generated by Ripa-Fagnano RDF station (L'Aquila, Italy). On the axis of ordering the electromagnetic frequency and on the axis of the abscissa the time of appearance of the registered signals. It highlights (in enlargement) the characteristics of the violet radio-anomaly recorded by the RDF station. In this case the appearance of electromagnetic signals that the detection system has highlighted in nicknaps, indicating the azimut of origin from central

Italy, with several hours of notice before earthquakes occur. The evidence of these emissions at a close time distance compared to the time of occurrence of the two earthquakes, indicates that these signals possess a close relationship with the seismic events in question. Credits: Radio Emissions Project, Permanent Foundation G. Giuliani.

Further important data series comes from Pontedera (Pisa, Italy) RDF station whose electromagnetic signals were recorded on December 24, 2020. Signals appearing at the electromagnetic frequency of $28 \mathrm{~Hz}$ and with orange azimut, indicating the seismic epicenter (as visible in Fig. 6). This signal, clearly, has appeared without notice and lasted about/an hour, as visible in the Fig. 14.

The data provided by the RDF monitoring system indicate that radio frequency monitoring between 0.01 and $28 \mathrm{~Hz}$ (SELF-ELF band) can give important predictive indications. The "pre-seismic" characteristics found on these signals were the following:

- Opposing a short distance from the seismic events.

- Greater intensity in $\mathrm{dB}$ with respect to the natural electromagnetic background.

- Different spectral modulation and footprint compared to the signals on the electromagnetic bottom.

\section{CONCLUSIONS}

It concludes that the association between the electromagnetic signals and the goniometric map of the RDF system is suitable for continuous monitoring of seismically active areas. Thanks to the RDF triangulation method there are potentially short-term seismic risk areas in a time interval of five days before the shock. The Italian RDF network has acquired important data, such as the azimutal one, indicating the direction of arrival of the signals themselves and the area within which the earthquakes would take place. The method is limits because it identifies a circumscribed area but not the epicentral point, at least for now. With the improvement of technology, the preparation of new monitoring stations and interdisciplinary studies, the RDF method arises as a candidate for the analysis of a crustial diagnosis and the study of seismic precursor candidates.

\section{THE FUTURE OF THIS RESEARCH}

It will be important, in the near future, extend this detection network not only in Italy, but also on an international scale, to better monitor electromagnetic emissions and make the RDF monitoring network on a global scale more efficient. It is still early in order to use the RDF network in order to predict the 
Volume 9 Issue 1 January 2021

identification of a precise real-time seismic epicenter: a goal, however, that can be approached in the future using more powerful computerized systems.

\section{REFERENCES}

[1]. V. Straser, D. Cataldi, G. Cataldi. (2018). Radio Direction Finding System, a new perspective for global crust diagnosis. New Concepts in Global Tectonics Journal, V. 6, No. 2, June 2018.

[2]. D. Cataldi, G. Cataldi, V. Straser. (2019). Radio Direction Finding (RDF) - Pre-seismic signals recorded before the earthquake in central Italy on 1/1/2019 west of (AQ). European Geosciences Union (EGU) General Assembly 2019, Seismology (SM1.1) General Contributions on Earthquakes, Earth Structure, Seismology, Geophysical Research Abstract, Vol. 21, EGU2019-3124, 2019, Vienna, Austria. HarvardSmithsonian Center for Astrophysics, High Energy Astrophysics Division, SAO/NASA Astrophysics Data System.

[3]. V. Straser, D. Cataldi, G. Cataldi. (2019). Registration of Pre-Seismic Signals Related to the Mediterranean Area with the RDF System Developed by the Radio Emissions Project. International Journal of Engineering Science Invention (IJESI), www.ijesi.org. Volume 8 Issue 03 Series. March 2019. PP 26-35. ISSN (Online): $2319-6734$, ISSN (Print): 2319 - 6726, 2019.

[4]. V. Straser, D. Cataldi, G. Cataldi. (2019). Radio Direction Finding (RDF) - Geomagnetic Monitoring Study of the Himalaya Area in Search of Pre-Seismic Electromagnetic Signals. Asian Review of Environmental and Earth Sciences, v. 6, n. 1, p. 16-27, 14 jun. 2019.

[5]. V. Straser, D. Cataldi, G. Cataldi. (2019). Electromagnetic monitoring of the New Madrid fault us area with the RDF system - Radio Direction Finding of the radio emissions project. New Concepts in Global Tectonics Journal, V7 N1, March 2019. pp43-62.

[6]. V. Straser, G. Cataldi, D. Cataldi. (2019). Namazu's Tail - RDF: a new perspective for the study of seismic precursors of Japan. Lulu Editore, 2019.

[7]. V. Straser, G. G. Giuliani, D. Cataldi, G. Cataldi. (2020). Multi-parametric investigation of preseismic origin phenomena through the use of
RDF technology (Radio Direction Finding) and the monitoring of Radon gas stream (RN222). An international journal for New Concepts in Geoplasma Tectonics, Volume 8, Number 1, May 2020, pp. 11-27.

[8]. D. Cataldi, G. G. Giuliani, V. Straser, G. Cataldi. (2020). Radio signals and changes of flow of Radon gas (Rn222) which led the seismic sequence and the earthquake of magnitude Mw 4.4 that has been recorded in central Italy (Balsorano, L'Aquila) on November 7, 2019. An international journal for New Concepts in Geoplasma Tectonics, Volume 8, Number 1, May 2020, pp. 32-42.

[9]. V. Straser, G. Cataldi, D. Cataldi. (2020). Radio direction finding for short-term crustal diagnosis and pre-seismic signals. The case of the Colonna earthquake, Rome (Italy). European Journal of Advances in Engineering and Technology, 2020, 7(7):46-59.

[10]. V. Straser, D. Cataldi, G. Cataldi. (2020). Radio Direction Finding (RDF) - Geomagnetic monitoring study of the Japanese area related to pre-seismic electromagnetic signals. New Concepts in Geoplasma Tectonics Journal. Vol. 8, No. 2, August 2020. pp119-141.

[11]. T. Rabeh, D. Cataldi, Z. Z. Adibin, G. Cataldi, V. Straser. (2020). International study Italy-Malaysia pre-seismic signals recorded by RDF - Radio Direction Finding monitoring network, before earthquakes: Mw 6.3, occurred at $111 \mathrm{~km} \mathrm{SW}$ of Puerto Madero in Mexico and Mw 6.3, occurred at $267 \mathrm{~km} \mathrm{NW}$ of Ozernovskiy in Russia, November 20, 2019. New Concept in Geoplasma Tectonics. Vol. 8, No. 2, pp.105-118. August 2020.

[12]. D. Cataldi, V. Straser, G. Cataldi, G. G. Giuliani, Z. Z. Adibin. (2020). Registration of Pre-Seismic Radio Signals Related To The Russian And Jamaican Earthquakes With The RDF System Developed By The Radio Emissions Project. International Advance Journal of Engineering Research (IAJER), Volume 3, Issue 9 (September - 2020), PP 01-30; ISSN 2360-819X.

[13]. V. Straser, D. Cataldi, G. Cataldi, G. G. Giuliani, J. R. Wright. (2020). Effects Of Hurricane Laura On The New Madrid Fault Area - Results Of 
Volume 9 Issue 1 January 2021

Electromagnetic Monitoring Through The RDF Network - Radio Direction Finding - And Arkansas Electromagnetic Monitoring Station. New Concepts in Global Tectonics Journal. Vol.8, No.3, pp.187-218, December 2020. ISSN 2202-0039.

[14]. G. A. Sobolev, V. M. Demin, B. B. Narod, and P. Whaite. (1984). Tests of Piezoelectric and Pulsed Radio Methods for Quartz Vein and Base-Metal Sulfides Prospecting at Giant Yellowknife Mine, N.W.T., and Sullivan Mine, Kimberly, Canada. Geophysics, vol. 49, no. 12, pp. 2178-2185. 1984.

[15]. M. B. Gokhberg, I. L. Gufeld, N. I. Gershenzon, V. A. Pilipenko. (1985). Electromagnetic effects in crustal fracturing. In its USSR Rept.: Earth Sci. (JPRS-UES-85-008) p 34 (SEE N86-12697 0342) Transl. into ENGLISH from Izv. Akad. Nauk SSSR: Fiz. Zemli (Moscow), no. 1, Jan. 1985.

[16]. P. Varotsos, K. Alexopoulos, K. Nomicos, M. Lazaridou. (1986). Earthquake prediction and electric signals. Nature, Volume 322, Issue 6075, pp. 120. 1986.

[17]. G. Cataldi. (2020). Precursori Sismici Monitoraggio Elettromagnetico. Kindle-Amazon, ISNB: $9798664537970 . \quad$ ASIN Code: B08CPDBGX9.

[18]. Britannica Online Encyclopædia field.https://www.britannica.com/ 